\title{
A participação dos jornais fronteiriços no processo de integração latino-americano ${ }^{1}$
}

\author{
Karla Maria Muller ${ }^{2}$ \\ UFRGS \\ kmmuller@orion.ufrgs.br
}

\begin{abstract}
Resumo: Os jornais produzidos e em circulação nos espaços urbanos conurbados e semi-conurbados das fronteiras nacionais brasileiras abordam, apresentam e participam da construção de um processo integracionista de fato, levando em conta os sujeitos locais, os diversos Campos Sociais e o contexto. Analisando os textos da mídia impressa produzida nesses territórios marginais, é possível perceber que o homem do lugar realiza movimentos no sentido de estabelecer uma interação efetiva com o outro. $O$ presente artigo tem por objetivo mostrar como os jornais fronteiriços, ao publicizarem estes procedimentos, 'trabalham' no sentido de solidificar a integração (ainda frágil) entre o Brasil e seus vizinhos, Uruguai, Argentina, Paraguai e Bolívia.
\end{abstract}

Palavras-chave: jornal local, mídia impressa, integração latinoamericana, fronteira.

Resúmen: Los periódicos producidos y en circulación en los espacios urbanos conurbanos y semi conurbanizados de las fronteras nacionales brasileras abordan, presentan y participan de la construcción de un proceso integracionista de hecho, tomando en cuenta a los sujetos locales, los diversos Campos Sociales y el contexto. Analizando los textos de los medios impresos producidos en esos territorios marginales, es posible percibir que el hombre del lugar realiza movimientos en el sentido de establecer una interacción efectiva con el "otro". El presente artículo tiene por objetivo mostrar como los periódicos fronterizos, al publicitar estos procedimientos, "trabajan" en el sentido de solidificar la integración (aún frágil) entre el Brasil y sus vecinos, Uruguay, Argentina, Paraguay y Bolivia.

Palabras clave: periódico local, medios impresos, integración latinoamericana, frontera.

${ }^{1}$ Trabalho apresentado no IV Congresso da SBPJOR, realizado na FABICO/ UFRGS novembro/ 2006.

2 Jornalista, Relações Públicas, Dra. em Ciências da Comunicação, Profa. e Pesquisadora do PPGCOM/ UFRGS; Editora da revista eletrônica INTEXTO www.intexto.ufrgs.br;

Representante da UFRGS no Comitê Acadêmico Mercosul Integração(CAMI) - Associação das Universidades Grupo Montevidéu (AUGM). Membro da Diretoria da Associação Riograndense de Imprensa (ARI) e do Instituto de Comunicação, Cultura, Educação e Formação Política Alberto André (IAA); Colaboradora do Centro de Estudos de Literatura e Psicanálise Cyro Martins / Projeto Fronteiras Culturais. 
Rèsumé: Le périodique produit ou en circulación dans le espace urbane, conurbane ou semi conurbane dans le frontière national bresiliene aborde, presente et participe dans le construction d'une procès integracioniste du fait, prendre en cosidération le sujet local, les diferents Champs Sociales et le contexte. Dans la analize de les textes de la presse produit dans cet territoire marginales, cest possible percevoir qui l'homme du local faire mouvementes dans le sens de établir une interacción efective avec le "autre". Le présent article ont pour objectif montrer come les périodique frontalier, "travaille" dans le sens du solidifie cet integración (encore fragille) avec le Brasil et son voisin, Uruguay, Argentina, Paraguay y Bolivia.

Mot-clés: journal local, presse, integration latin-americain, frontière.

Abstract: The newspapers published, which circulate in the frontier spaces of Brazilian national frontier state, present and communicate the construction of the process integrationist, taking into account the local people, and the variety of Social Field and context. After analysing the press media contents published in the frontier territory, it is possible to perceive that the local man makes movements towards the establishment of an effective interaction with the "other". The present article has the objective of showing how the border newspapers, which publish the integration movements ideas "work" towards the idea of solidifying the integration (which is still fragile) among Brazil and the other neighbor countries, such as Uruguay, Argentina, Paraguay and Bolivia.

Key-words: local newspaper, press media, Latin American integration, frontier.

\section{Introdução}

Espaços urbanos de fronteiras nacionais despertam curiosidades por vários aspectos: oscilações entre o local e o internacional, presença constante de um estrangeiro, movimentos de integração e isolamento, alteridade e intolerância, aproximações e distanciamentos, marcos divisórios reais e simbólicos, entre outros. Cidades como Santana do Livramento e Rivera, Uruguaiana e Paso de Los Libres, Ponta Porã e Pedro Juan Caballero, Corumbá e Puerto Quijaro, localizadas nos contornos do território brasileiro e de seus vizinhos - Uruguai, Argentina, Paraguai e Bolívia - nos levam a pensar sobre os fazeres e os dizeres do homem do lugar para tornar possível o convívio entre cidadãos de nacionalidades marcadamente diferentes. 
Através de um exercício diário, o fronteiriço extrapola qualquer discurso que pregue a integração, coloca em prática ações surgidas de uma necessidade premente, descobre e inventa formas de ultrapassar barreiras, enfrentando dificuldades de modo a tornar viável a vida na fronteira. As trocas estabelecidas nestes pontos de contato alertam que as divisões geopolíticas estabelecidas por decorrência da criação dos Estados-Nacionais não são mais suficientes para atender às novas configurações, principalmente dos espaços urbanos.

Em regiões como a fronteiriça a vida passa a ser redesenhada de modo a satisfazer as exigências do momento e do local. A partir da existência de um lugar diferenciado como esse, verifica-se a relação, aparentemente fraterna, de duas ou mais nações com hábitos e costumes distintos, dividindo um mesmo espaço, constituindo uma nova comunidade que oscila entre o local e o internacional permanentemente.

Para identificar-se como membro deste grupo o fundamental não é pertencer a uma mesma nacionalidade. Com certeza, há elementos que destacam a especificidade do ser fronteiriço garantindo uma identidade própria e privilégio desse que sabe e reconhece o que é viver na faixa de divisa do território nacional e lado a lado com um outro, membro da nação vizinha.

Neste caso, podemos tomar como exemplo os quatro espaços acima citados, com elementos semelhantes, mas também com profundas peculiaridades, dignas de estudo no que tange às características de uma cultura e uma identidade que possam vir a ser consideradas como fronteiriças.

Livramento-Rivera assim como Ponta Porã-Pedro Juan Caballero são consideradas cidades conurbadas, isto é, áreas urbanas constituídas, neste caso, de apenas duas cidades, cujos limites geográficos 'fundem-se', fazendo com que a vida de seus habitantes tenha como palco um espaço que pode ser definido como comum. Nele as relações institucionais, sociais, pessoais, comerciais etc. mesclam-se, criando (não raramente) uma complementaridade entre as duas cidades. Nos espaços de Uruguaiana-Libres e Corumbá-Puerto Quijaro, o processo é semelhante embora haja um pouco mais de distanciamento físico entre os dois centros urbanos, por isso estas cidades podem ser denominadas de semi-conurbadas. 
É neste sentido que podemos dizer que, numa primeira leitura, as fronteiras, isto é, os limites aqui tratados, estão presentes mais no imaginário do que nas práticas cotidianas. Com freqüência, estas divisas - ruas ou rios - passam despercebidas pelo olhar de um forasteiro. Por isso, tratamos estas duplas de municípios como quatro espaços, nos quais a vida diária se processa considerando as cidades como uma só.

O recorte espacial aqui apresentado possibilita discutir quais os movimentos que a população que habita as fronteiras nacionais de países pertencentes ao Cone Sul da América Latina realiza para estabelecer uma integração de fato. Estes movimentos podem indicar características constituintes de uma cultura e uma identidade fronteiriça que pode passar a ser considerada como referência quando pensamos nas fronteiras nacionais e, ao mesmo tempo, apontar especificidades, definindo elementos peculiares a cada um dos espaços de ligação do Brasil com seus diferentes vizinhos.

Para verificar o entrelaçamento entre os diversos Campos Sociais das áreas urbanas de fronteiras nacionais elegemos como objeto de análise a mídia local. Ela participa ativamente da construção da realidade a partir dos modos e estratégias de operação que aciona e através dos acontecimentos que publiciza em seus programas, em suas páginas, em seus textos e discursos.

\section{Textos dos Jornais Fronteiriços}

Para fazermos uma discussão sobre algumas das práticas culturais dos fronteiriços que consideramos, a priori, distintas das realizadas por outros grupos, passemos para a apresentação de textos veiculados pela mídia impressa local. Nosso interesse neste momento é identificar algumas ações implementadas ou valorizadas pela população fronteiriça que podem ser caracterizadas como movimentos específicos do lugar e situações nas quais é perceptível a integração entre os grupos envolvidos. Através de eventos, das ações, dos discursos e das práticas socioculturais instala-se um processo inclusivo entre os habitantes - as cidades, as instituições e/ou os países - envolvidos naqueles espaços, mas neste caso, a partir do fenômeno ali presente: as fronteiras nacionais. 
O material selecionado foi extraído de jornais produzidos no ano de 2004 em espaços de fronteiras do território brasileiro3, que tem como público-alvo o fronteiriço de ambos os lados da linha divisória, mas com ênfase no leitor brasileiro. São eles: A Platéia (de Livramento/ RS), O Jornal de Uruguaiana (de Uruguaiana/ RS), Jornal da Praça (de Ponta Porã/ MS) e Folha de Corumbá (de Corumbá/ MS). Na época (e ainda hoje), assim como em A Platéia, o Jornal da Praça produz uma seção em espanhol4, o que já configura uma atitude diferenciada, destinada e com vista a atender o habitante do lugar5.

Alguns itens já foram analisados em trabalhos anteriores e apresentados em fóruns de discussão e/ ou publicados como resultados parciais de uma investigação que está em curso. No início das reflexões constatou-se que os movimentos de aproximação e distanciamento se sucedem paradoxalmente. Ações que definem a interação, e até mesmo a integração - ou seja, o processo 'institucionalizado' - entre os habitantes de ambos os lados das bordas nacionais são por vezes visíveis. Porém, em determinadas situações, é difícil detectar, através das práticas culturais colocadas em marcha, qual a real intenção dos grupos locais para garantir sua diferenciação como comunidade fronteiriça, ou seja, são invisíveis ${ }^{6}$.

Índices como meio ambiente, língua, imigrantes (dos quais os grupos mais aparentes são os árabes, palestinos e libaneses), são trabalhados pela mídia local muito no sentido de reforçar os laços de integração dos povos envolvidos. Entretanto, não podemos negar que as situações ligadas ao crime são marcantes e delicadas de serem abordadas nos espaços dessas fronteiras nacionais. Assuntos como o tráfico de drogas, o abigeato, roubos, contrabando assim como outros temas focados na economia - como, por exemplo, a febre aftosa, o cultivo da soja ou do arroz - são

\footnotetext{
3 Este material faz parte do corpus da pesquisa em desenvolvimento junto ao PPGCOM/ UFRGS: 'Comunicação, cultura(s) e identidade(s) fronteiriças'.

4 Salientamos que estes dois jornais possuem uma seção em espanhol, mas em outros momentos, por exemplo, O Jornal de Uruguaiana também possuía seu caderno em espanhol. 5 Seria ingenuidade nossa pensar que a atitude de as empresas abrirem espaço para seções na língua dos habitantes do país vizinho seja considerada apenas como uma ação de responsabilidade social destas indústrias culturais. Diz respeito também aos seus interesses econômicos, como destaca Traquina (2001).

${ }^{6}$ Estas conclusões foram apresentadas no III Congreso Panamericano de Comunicación (UBA, 2005) e publicadas em forma de artigo (em espanhol) e disponível na revista digital Topos \& Tropos (MÜLLER; OLIVEIRA, 2005).
} 
inevitáveis, pois também fazem parte do cotidiano, das práticas e dos processos sociais dessas comunidades7.

Por isso, dando prosseguimento à discussão cujo objeto são os jornais locais, a cultura e a identidade fronteiriças, listamos agora outros aspectos que podem ser verificados nos quatro jornais e representam a preocupação com o fenômeno fronteira e a condição de ser fronteiriço. Remetemos então a questão para a segurança, o turismo, o poder público federal e a economia.

a) Segurança Pública

Um dos aspectos que tem sido (cada vez mais) motivo de preocupação para o cidadão em geral é a segurança pública. Nos espaços de fronteiras nacionais podemos dizer que este tema é ainda mais delicado devido ao tráfico de drogas e ao contrabando. Passemos então aos jornais fronteiriços para verificar como isto é tratado.

“Foragido mata policial uruguaio e acaba internado" (A Platéia, 24-25/ Fev/ 2004, Capa). A matéria, que é desenvolvida nas páginas internas do periódico, informa que, graças a uma ação conjunta da polícia brasileira e uruguaia, o assassino foi preso. Ressalta também, o fato de policiais brasileiros participarem do enterro, demonstrando solidariedade ao colega vitimado. Neste texto, cabe destacar, além do trabalho feito em parceria, que A Platéia trata a notícia em duas seções, sendo uma delas a seção escrita em espanhol.

No texto "Mulher serve de 'isca' para mais um roubo de motocicleta" (O Jornal de Uruguaiana, 24/ Nov/ 2004, p. 13), o destaque ficou por conta de os assaltantes terem se aproveitado do espaço por ele ser uma divisa nacional, o que obrigou a vítima (um brasileiro, que se dirigiu para o lado argentino) a buscar socorro junto aos policiais daquele país em Paso de Los Libres. Detalhe: a mulher de que trata o título da notícia e que serviu de 'isca' para o assalto, também era (aparentemente) brasileira, como fica declarado no texto jornalístico.

\footnotetext{
7 Estas conclusões foram apresentadas no 'Seminário Internacional Fronteiras Culturais: o espaço urbano' (USP, 2005) e estão publicadas em forma de artigo na revista digital INTEXTO (MULLER, 2005).
} 
Na matéria cujo título é "Traficantes cariocas estariam se fortalecendo na fronteira" (Jornal da Praça, 31/ Jan - 10/ Fev/ 2004, p. 06) constata-se que a fronteira é um espaço propício à ação de narcotraficantes e dá destaque ao fato de ser fundamental o estabelecimento de um trabalho conjunto entre as polícias dos dois países.

Com o título "Fronteira, um caso de segurança" (Folha de Corumbá, 18/ Set/ 2004, p. 11), o jornal corumbaense reclama da falta de policiamento que expõe o cidadão local às "conturbadas" relações com a Bolívia, contribuindo para a criação de uma "imagem negativa lá fora" da "Capital do Pantanal". De outro modo, a matéria ressalta que uma das causas dessa relação tensa entre a população local é a situação de empobrecimento que assola os moradores de ambos os lados da linha divisória, ocasionando desemprego e favorecendo o "tráfico formiga e ao vício".

b) Potencial Turístico

Nos quatro jornais encontramos exemplo na fronteira sendo vista como potencial turístico para a região. Vejamos:

Sob a cartola "Ventas", a matéria colocada na seção em espanhol e intitulada “También fue un día especial para los artesanos" (A Platéia, 21/ Set/ 2004, p. 15 Geral), destaca os bons índices de vendas para os artesãos localizados na área do Parque Internacional, por ocasião das comemorações da Semana Farroupilha, data marcante para os gaúchos, em especial os riograndenses, graças ao grande número de visitantes que compareceram às festividades.

Em “Os turistas já começaram a passar por Uruguaiana” (O Jornal de Uruguaiana, 08/ Dez/ 2004, p. 11 - Geral), o periódico uruguaianense faz alusão aos turistas argentinos que passam por ali nos meses de verão, mas que poderiam desfrutar, por exemplo, da gastronomia local - leia-se de Uruguaiana e de Paso de Los Libres - "um espetáculo de gastronomia fronteiriça”.

"Corumbá tem pacote de carnaval" (Folha de Corumbá, 31/ Jan/ 2004, p. 07 - Geral), é o título da matéria que ressalta as belezas que a cidade oferece, em especial a união da folia com as belezas naturais da região pantaneira, incluindo a pesca, o passeio de barco pelo rio Paraguai, e a condição de região de fronteira do Brasil com a Bolívia. 
No jornal de Ponta Porã, o turismo não é tratado diretamente. Entretanto, a partir de eventos promovidos na cidade, percebe-se a oportunidade: "Encontro reúne milhares de pessoas no CTG” (Jornal da Praça, 24-25/ Jul/ 2004 - Capa).

Há um potencial turístico nestes espaços que nem sempre sabe ser explorado. As cidades, por serem fronteiriças, oferecem a possibilidade de compra nos free shops das cidades vizinhas. Em Rivera, Libres, Pedro Juan e Puerto Quijaro, ao simples gesto de atravessar a rua por suas calçadas ou cruzar o rio através da ponte, o visitante pode - como normalmente o faz - realizar compras de produtos estrangeiros a preços razoáveis. Dificilmente um turista deixa de aproveitar a oportunidade para adquirir mercadorias que só podem ser compradas no exterior com um preço mais acessível ou nas Zonas Francas, como é o caso (claro que dependendo da cotação e das variações cambiais o favorecimento é para um ou outro lado da fronteira). Nestes espaços, o exterior está há poucos metros ou passos.

c) A 'mão’ do Poder Público Federal

Pelo fato de os espaços aqui tratados se configurarem em divisas nacionais, não raras vezes, recebe destaque os movimentos realizados pelos governos federais que envolvem diretamente a vida na fronteira, como poderemos verificar a seguir.

"Brasil y Uruguay buscan integración desde la realidad local de frontera" (A Platéia, 2-3/ Mai/ 2004, p. 39 - Español), é o título da matéria publicada nas páginas em espanhol do jornal santanense. O texto ressalta a importância de os governos federais reconhecerem que a vida do homem fronteiriço é diferenciada se comparada com a dos habitantes de outros espaços, por isto a necessidade de uma "jurisprudencia especial para esta frontera especial", como reproduz o jornal, a partir das palavras do "Canciller uruguayo, ante las autoridades de los dos paises". $\mathrm{Na}$ ocasião, foi instalado o "Centro para los Estudios y Divulgación de los Aspectos Jurídicos de la Integración en el Area Fronteriza", iniciativa importante, segundo as 'palavras do jornal' e que contou com a participação do embaixador do Brasil no Uruguai, o intendente de Rivera, entre outras autoridades representando o Poder Judiciário.

Na matéria "Ministra das Minas e Energia visita Uruguaiana" (O Jornal de Uruguaiana, 22/ Set/ 2004, p. 03 - Política - Geral) relata a visita da Ministra Dilma 
Housseff na cidade, que se pronuncia com relação à termoelétrica instalada em Uruguaiana que trabalha a quem de sua capacidade, pois depende da Argentina e da Bolívia, pois o gás proveniente desta passa por aquela. O dilema existe e preocupa a população local que seria beneficiada com o investimento e poderia usufruir deste combustível, mas a questão não é de fácil resolução, pois envolve negociações entre os três países.

Em "Liberado R \$ 400 mil para combater aftosa na fronteira" (Jornal da Praça, 08/ Set/ 2004, p. 7B - Geral) o jornal de Ponta Porã aborda uma das questões mais delicadas no que se refere à agropecuária da fronteira oeste: o controle à febre aftosa. O texto traz as palavras do representante do governo brasileiro, Ministro da Agricultura na época, Roberto Rodrigues: “Tomamos a decisão política de fazer a proteção sanitária do Mato Grosso do Sul para evitar a qualquer custo a entrada da doença em território brasileiro".

“Corredor bioceânico torna Corumbá centro comercial” (Folha de Corumbá, 21/ fev/ 2004) é o título da matéria que dá destaque à iniciativa do Governo Lula de abrir um corredor que garanta o comércio entre São Paulo e os países latinoamericanos, que passará pelo município corumbaense. A proposta é integrar o estado do Mato Grosso do Sul, em especial as cidades fronteiriças, nessa proposta que prevê um intercâmbio de mercadorias através da retomada do transporte fluvial.

d) Perspectiva Econômica

Sob vários aspectos, a fronteira é tratada a partir de uma perspectiva econômica. Em muitas das matérias selecionadas para compor outros itens aqui propostos, a fronteira é vista como um grande potencial econômico, tanto por autoridades locais, como estaduais e federais. Nem sempre isto fica claro, mas de modo geral, o Campo Econômico é um dos mais fortes, principalmente no que se refere ao Mercosul. Trazemos a seguir, alguns exemplos:

"Comeri inaugura base de vendas com recepção no hotel Jandaia" (A Platéia, 2-3/ Mai/ 2004, p. 13 - Geral) é o título da reportagem que informa a instalação da Cooperativa Médica de Rivera em Livramento. A iniciativa é tratada como investimento, e Livramento é visto como "Ponto estratégico" para a captação de novos sócios e usuários: "Em companhia de autoridades civis e policiais, eles [os 
médicos uruguaios, em sua grande maioria riverenses] manifestaram sua satisfação em instalar um ponto de vendas em Santana do Livramento”.

Na matéria assinada por Roberto Ferreira, "O Direito Universal do homem garante a liberdade de compra" (O Jornal de Uruguaiana, 10/ Jul/ 1004, p. 11), a critica diz respeito ao impedimento de o povo fronteiriço poder adquirir gêneros alimentícios para consumo próprio do outro lado da Ponte, devido à normatização emanada pelos órgãos do governo federal brasileiro. O texto conclama o "Comitê de Fronteira do Corpo Consular" que parta em defesa dos habitantes locais.

A reportagem "Uma atração para investidores brasileiros" (Jornal da Praça, 15-16/ Mai/ 2004, Caderno 3 - Capa) destaca o potencial da cidade paraguaia de Concepción, próxima a Pedro Juan, para investidores brasileiros. Com suas "terras férteis e estrategicamente localizadas no contexto econômico continental", a cidade torna-se interessante àqueles que acreditam no agronegócio. O texto ressalta a presença dos brasileiros na região através, inclusive, da culinária gaúcha que completa o "festivo clima de cores verde e amarelo que se respira em Concepción".

O texto "Brasil e Bolívia discutem navegação na fronteira" (Folha de Corumbá, 1\% / Mai/ 2004, p. 07) estampado nas páginas do jornal fronteiriço, aborda o Tratado estabelecido entre os dois países que prevê a ligação da Bolívia com o mar através da ligação fluvial com o Brasil. A temática envolve implementação de ações de ambos em nível federal, estadual e local e deve levar em conta, não somente as questões econômicas, mas também os impactos no meio ambiente, pensando inclusive na melhoria da qualidade de vida dos moradores da região.

\section{Exercício Interpretativo}

Dentro do que foi 'recortado' da veiculação dos jornais produzidos e em circulação predominantemente nos espaços da fronteira oeste brasileira, e 'colado' no texto aqui apresentado, cabem algumas considerações conceituais que virão ao encontro de nossa leitura dessa mídia impressa local. A proposta é, a partir deste exercício interpretativo, detectar as peculiaridades mais visíveis das práticas colocadas em curso pelos habitantes e instituições fronteiriças - e aqui incluímos os meios de comunicação locais - que lhes diferenciam de outros lugares. 
Para nós, estas fronteiras, tanto os espaços conurbados de LivramentoRivera e Ponta Porã-Pedro Juan, como os semi-conurbados de Uruguaiana-Libres e Corumbá-Puerto Quijaro, configuram-se efetivamente como "fronteiras-vivas". Enquadram-se no conceito de Iturriza (apud PADRÓS, 1994, p. 69), que as caracteriza como permeáveis, de tensão ou acumulação, zonas isoladas e afastadas dos centros dinâmicos nacionais, com escasso e desigual desenvolvimento econômico (em relação ao país), estão próximas de áreas de países vizinhos de conformação humana e geográfica semelhantes, etc. São espaços nos quais as barreiras já sofreram a ação do homem através da interação dos agentes fronteiriços, estimulando dinâmicas específicas, em sua grande maioria informais e, não raras vezes, paliativas e temporárias, mas que podem passar a ser duradouras.

Embora tenhamos reproduzido somente o título das matérias não temos a intenção de realizar um exercício interpretativo sobre ele como propõe Mouilland (1997, p. 99-116) e que o considera como "a inscrição do jornal por excelência”. Da mesma forma, embora saibamos a importância da análise das imagens, isto é, do discurso fotográfico no contexto do jornal, conforme aponta Sousa (2004), nosso objetivo não é nos deter neste aspecto. Nossa proposta foi de apontar, a partir de itens previamente definidos, algumas das temáticas estampadas nas páginas externas e internas dos jornais e o conjunto da informação apresentada. Dessa forma é possível pensar o fenômeno fronteira, verificando quais são as ações adotadas por seus agentes locais para driblar as dificuldades decorrentes desse fenômeno e seus desdobramentos no intuito de sustentar, através de suas práticas, o processo integracionista.

No item segurança pública, a manifestação dos quatro jornais destaca a importância das ações serem organizadas conjuntamente com a polícia de ambos os lados da fronteira. A facilidade que os contraventores têm de ultrapassar a linha divisória amplia a possibilidade de buscar refúgio do outro lado e ficar impune à força da lei. Recebe destaque também o fato de não ser fácil identificar a nacionalidade desses bandidos, não raras vezes e quando oriundos da região, podem desfrutar de dubla cidadania. Outro aspecto interessante diz respeito ao reconhecimento da aproximação entre os povos vizinhos no que se refere ao empobrecimento da região, como destaca o texto de a Folha de Corumbá, justificando a criminalidade na região. 
Em situações como estas o sentimento de rivalidade que pode existir em relação ao outro fica diluído, tornando-o (mesmo que momentaneamente) indiferente às identidades nacionais. A relação hostil é mais 'alimentada' no discurso de mídias que não as locais. Isto foi possível constatar em outros estudos cujo objeto de pesquisa constituiu-se de jornais produzidos em cidades configuradas como capitais estaduais (JACKS; MACHADO; MÜLLER, 2004).

Sobre o turismo da região fronteiriça, percebe-se que ao se referir aos artesãos locais, às belezas naturais da região, à gastronomia local ou até mesmo às festividades realizadas pelos Centros de Tradições Gaúchas - CTGs, fica claramente posto (ou subentendido) o potencial que o espaço oferece quando visto de modo integrado. O simples fato de existir um outro país, um povo com outra nacionalidade, falando outra(s) língua(s), a poucos metros, dá um diferencial às cidades fronteiriças que pode ser encarado como investimento turístico para os municípios e o comércio local/ internacional, de lá e de cá, fortalecendo a economia da região.

Na argumentação trazida pelo jornal de Corumbá, a ligação dos países se dá pelas belezas naturais que o Pantanal oferece. Embora o turismo possa representar uma fonte de receita para a região (OLIVEIRA, 1998), neste espaço ele carece de maiores investimentos. A exuberância do lugar é visível não apenas nas cores que tingem e decoram a fauna e a flora pantaneiras, mas também pela sua variedade, como destaca Renato Báez (1975) (1976), e em especial, pela possibilidade - ainda de uma pesca farta que atraí os aficionados pelo esporte.

No que se refere aos aspectos vinculados à cultura e às tradições gaúchas como os festejos da Revolução Farroupilha, a gastronomia campeira, as danças típicas, a música tradicionalista etc. - verifica-se um elemento de ligação entre os povos das regiões fronteiriças. Pode-se dizer que estes hábitos e costumes são muito propagados pelos riograndenses, mas também vividos e cultivados de modo semelhante por uruguaios, argentinos e, em certa medida, pelos paraguaios. Através do gauchismo, como analisa Oliven (2006), as marcas culturais da região sul do Brasil, que se estendem pela fronteira oeste, põem em contraste esta cultura regional com outras em nível nacional, definindo uma aproximação com seus vizinhos da Bacia do Prata, e reforçando um distanciamento, apontando para a diversidade cultural brasileira, na qual a cultura gaúcha está claramente inscrita. 
Quando a temática envolvendo o Poder Público é tratada, questões que extrapolam as decisões em nível local, como as dos exemplos aqui trazidos, os atores chamados a depor são representantes do Poder Executivo e Judiciário Federal. Percebe-se que em três dos quatro casos - termoelétrica/ gás boliviano, agropecuária/ febre aftosa, corredor bioceânico/ navegação fluvial - embora a ênfase fique a cargo do Campo Político, o Campo Econômico está diretamente implicado. Em uma das matérias apenas a temática mais importante está ligada à integração dos habitantes dos espaços de fronteiras nacionais que devem ser vistos e tratados de modo diferenciado. Neste caso, o Judiciário e seus representantes são chamados à cena com o propósito de criar alternativas jurídicas (e legais) que dêem respaldo às ações dos agentes do lugar para que não se configurem como infrações e sim como alternativas para a região.

Por um lado, verifica-se a estratégia adotada pelos jornais de acionar enunciadores, desobrigando-se (como emissor) destes enunciados, pois como acrescenta Verón, “um mesmo emissor poderá, em discursos diferentes, constituir enunciadores diferentes, conforme, por exemplo, o alvo visado" (2004, p. 218). Por outro lado, questões que dizem respeito à fronteira são redimensionadas e jogadas para o macro, obrigando os poderes federais a se posicionarem no que tange à resolução das mesmas.

No último item, ou seja, numa perspectiva econômica, identificam-se entrelaçamentos (inevitáveis) entre os Campos Sociais para tratar o fenômeno fronteira e os sujeitos locais, levando em conta questões econômicas, políticas, sociais e culturais entre outras. Sabemos que esta é a trama que constitui o tecido social. O que vale ressaltar é a clareza com que isto está posto através das práticas dos habitantes dos espaços de fronteira e apresentadas nos textos da mídia impressa local.

Observando o enlace acima citado, torna-se evidente que os esforços para pensar a fronteira e o fronteiriço de modo especial solicitam um empenho conjunto das entidades locais principalmente, como também das regionais e federais. Indo um pouco além, e conforme destaca Albuquerque (apud FINQUELIEVICH, 2005, p. 09), as administrações locais devem superar seu papel tradicional como provedoras de serviços básicos, complementando estas funções com outras que favoreçam um 
ambiente inovador territorial, tendo como objetivo contribuir com o desenvolvimento de atividades produtivas dinâmicas e a difusão de uma cultura local desenvolvimentista.

Isso assinala para um processo integracionista que extrapole o aspecto econômico e político, como destacamos no início da discussão, que vai ao encontro do que propõe Roncagliolo: "são três os termos sobre os quais se constroem a sociedade global: o mercado, a democracia e os direitos humanos. Nos três se vive a cessão de soberanias nacionais em benefício de instâncias supranacionais" (2003, p. 125-126). E neste aspecto, os meios de comunicação podem ser "instrumentos de adormecimento ou conscientização" (MONTIEL, 1993, p. 250), colaborando para que tanto o poder público como as organizações em geral e a sociedade civil assumam uma postura diferenciada de inclusão com relação aos espaços e aos habitantes dos espaços fronteiriços.

Percebe-se, como traz o exemplo de O Jornal de Uruguaiana, que entidades e órgãos oficiais são criados para resolver impasses de âmbito local, mas envolvendo o internacional, porém nem sempre são atuantes. É em situações específicas, nas quais a comunidade local se sente abandonada e relegada a um segundo plano, que a pressão exercida pelos moradores do lugar, utilizando-se inclusive das páginas do jornal local para se fazer ouvir, torna-se fundamental para reverter o quadro.

Outra questão observada no texto jornalístico, e no mínimo curioso, é o fato de os brasileiros estarem avançando no território paraguaio e explorando suas riquezas, suas terras, principalmente por sua localização, em se tratando de América Latina. O que fica para uma reflexão mais aprofundada é em que medida estes investimentos se realizam como parcerias. Temos outros exemplos (como a discussão que vem sendo travada entre os governos federais com relação à instalação da Petrobrás em território boliviano, extraindo e comercializando suas riquezas naturais) que sinalizam para a preocupação em estabelecer acordos simétricos entre os participantes, de modo a evitar conflitos e beneficiar moradores de ambos os lados e os investidores e países envolvidos. E neste aspecto, devem ser chamados ao debate - e aberto espaço nos meios de comunicação - não só os investidores e as autoridades, mas toda a sociedade organizada, dando voz as mais variadas instituições. 


\section{Considerações Finais}

A caminhada percorrida neste breve texto foi direcionada para a análise de textos veiculados nos jornais, produzidos e em circulação nas fronteiras do Brasil com quatro países lindeiros, destacando alguns elementos que podem ser considerados como constitutivos da cultura e da identidade fronteiriça, isto é, práticas que colaboram para sustentar o processo integracionista latino-americano. $\mathrm{O}$ que oferecemos aqui foi um pequeno recorte dessa idéia, a partir dos textos jornalísticos apresentados pela mídia impressa local de quatro diferentes espaços geográficos. Todos caracterizados por localizarem-se em áreas urbanas da linha de divisa dos territórios nacionais.

Os itens analisados e subscritos sobre uma ainda grosseira classificação segurança, turismo, economia e poder público - auxiliam na composição do mosaico constituído pelas práticas socioculturais colocadas em curso por aqueles que vivem diariamente uma oscilação identitária - de uma identidade nacional para uma identidade local fronteiriça e vice-versa. São pessoas que sobrevivem com o dilema permanente - e muito presente, embora nem se dêem conta disso - de assumirem a todo instante uma posição que pressupõe um outro, ou seja, de se verem para poderem, a partir de uma identificação, diferenciarem-se deste outro. Uma relação de respeito, de alteridade, de solidariedade que divide espaço com sentimentos de rivalidade, de tensão, de enfrentamento (na maioria das vezes, contido).

Tentar analisar a fronteira é isso: tarefa complexa que deve acompanhar a dinamicidade do fenômeno e a flexibilidade dos sujeitos que o (re)edificam diariamente. Este exercício tem sido feito por estudiosos de diversas áreas do conhecimento no que tange à discussão sobre integração, com destaque para os países da América do Sul, como descreve Devés Valdés (2004).

No caso aqui apresentado, a proposta parte do olhar do Campo da Comunicação, tendo como preocupação primordial analisar o papel da mídia impressa local nesse processo, considerando-a elemento ativo que dita quais os acontecimentos que têm o caráter de noticiabilidade, quais os sujeitos que entrarão em cena (e quando) e como os discursos serão compostos, presumindo um possível leitor para os seus textos. O palco é o espaço fronteiriço no qual os atos vão se 
sucedendo, na apresentação de diferentes acontecimentos, criando momentos amenos e situações de clímax, na busca por desenlaces agradáveis. É através da construção dessa realidade que se dão as representações sociais, ensaiadas e assumidas pelos agentes locais ao desempenharem seus papéis. Os textos e as páginas dos jornais locais são algumas das formas sob as quais os conceitos sobre fronteira vão sendo reforçados (ou negados). Os periódicos podem - e devem - ser considerados partícipes desta integração. A partir do local eles dão visibilidade às práticas socioculturais daqueles sujeitos, trazem informações, contribuem com a construção da realidade, dando forma e sentido a uma cultura, a uma identidade e a um espaço, no caso específico, com marcas de fronteiriços, demonstrando como é possível estabelecer de fato a integração em nível supranacional.

\section{Referências}

BÁEZ, Renato. Corumbá: nótulas e depoimentos. Corumbá: s/ ed., 1976.

BÁEZ, Renato. Corumbá: reminiscências e impressões. Corumbá: s/ ed., 1975.

DEVÉS VALDÉS, Eduardo. El piensamiento latinoamericano en el siglo XX: entre la modernización y la identidad. Buenos Aires: Editorial Biblos, 2004.

FINQUELIEVICH, Susana (coord.). Desarrollo local en la sociedad de la información: municipios e Internet. Buenos Aires: La Crujía, 2005.

JACKS, Nilda A.; MACHADO, Marcia B.; MÜLLER, Karla M. Hermanos, pero no mucho: el periodismo narra la paradoja de la fraternidad y rivalidad entre Brasil y Argentina. Buenos Aires: La Crujía, 2004.

MONTIEL, Edgar. América en la geopolítica de las culturas. In: COLOMBRES, Adolfo (coord.). América Latina: el desafío del tercer milenio. Buenos Aires: Ediciones del Sol, 1993, p. 245-260.

MOUILLAUD, Maurice. O título e os títulos. In: MOUILLAUD, Maurice; PORTO, Sérgio D. et alli (org.). O Jornal: da forma ao sentido. Brasília: Paralelo 15, 1997, p. 99-116.

MULLER, Karla M. Espaços conurbados de fronteiras nacionais: 'leituras' de jornais locais. In: MÜLLER, Karla M. (editora). Revista eletrônica INTEXTO. No ${ }^{\circ} 13$. Porto Alegre: PPGCOM/ UFRGS, 2005. Site: www.intexto.ufrgs.br 
MULLER, Karla M.; OLIVEIRA, Tito Carlos M. Integración latinoamericana: a partir y a través de la comunicación y las fronteras. In: HAIQUEL, Miguel A. (editor). Revista electrónica Topos y Tropos. No .6 . Córdoba: T y T Editora, 2005. Site: www.toposytropos.com.ar/N6/tesis.htm

OLIVEIRA, Tito Carlos M. Uma fronteira para o pôr-do-sol: um estudo geoeconômico sobre a região de fronteira. Campo Grande: Ed. UFMS, 1998.

OLIVEN, Ruben George. A parte e o todo: a diversidade cultural do Brasil-nação. $2^{\text {a }}$ ed. Petrópolis: Vozes, 2006

PADRÓS, Enrique Serra. Fronteiras e integração fronteiriça: elementos para uma abordagem conceitual. In: Revista do Instituto de Filosofia e Ciências Sociais. V. 17, n. ${ }^{0}$ 1/ 2, Jan/ Fev, Porto Alegre, 1994.

SOUSA, Jorge Pedro. Introdução à análise do discurso jornalístico impresso: um guia para estudantes de graduação. Florianópolis: Letras Contemporâneas, 2004.

TRAQUINA, Nelson. O estudo do jornalismo no século XX. São Leopoldo: Ed. Unisinos, 2001.

VERÓN. Eliseo. Fragmentos de um tecido. São Leopoldo: Ed. Unisinos, 2004.

RONCAGLIOLO, Rafael. Problemas de la integración cultural: América Latian. Buenos Aires: Grupo Editorial Norma, 2003. 